\title{
Types of Arcs in Complement of a Fuzzy Graph
}

\author{
K.R. Sandeep Narayan,* M.S. Sunitha**
}

\begin{abstract}
Connectivity has important role in the area of applications of fuzzy graphs such as fuzzy neural networks and clustering. Different types of arcs such as $\alpha, \beta, \delta$ and fuzzy bonds are analyzed in a fuzzy graph $G$ and its complement.
\end{abstract}

Keywords: Fuzzy Tree, Complement of a fuzzy graph, Fuzzy Bridge, a-strong arc, Fuzzy bonds.

\section{Introduction}

The notion of fuzzy graph was introduced by Rosenfeld in the year 1975.[1] Fuzzy analogues of many structures in crisp graph theory, like bridges, cut nodes, connectedness, trees and cycles, etc were developed after that. Fuzzy trees were characterized by Sunitha and Vijayakumar.[4] The authors have characterized fuzzy trees using its unique maximum spanning tree. A sufficient condition for a node to be a fuzzy cut node is also established. Center problems in fuzzy graphs, blocks in fuzzy graphs and properties of self complementary fuzzy graphs were also studied by the same

*Department of Mathematics, Jyothi Engineering College, Thrissur 679 531; appunaran@yahoo.com

** Department of Mathematics, National Institute of Technology, Kozhikode 673 601; sunitha@nitc.ac.in

Received: February 2011; Revised: September 2011 
authors. They have obtained a characterization for blocks in fuzzy graphs using the concept of strongest paths.[6] Bhutani and Rosenfeld have introduced the concepts of strong arcs, fuzzy end nodes and geodesics in fuzzy graphs.[3] The authors have defined the concepts of strong arcs and strong paths. As far as the applications are concerned (information networks, electric circuits, etc.), the reduction of flow between pairs of nodes is more relevant and may frequently occur than the total disruption of the flow or the disconnection of the entire network. In view of this, in order to study such properties of information networks, Rosenfeld [2] defined the concept of a fuzzy cut node as a node in a fuzzy graph whose removal reduces the strength of connectedness between some pair of nodes. Similarly a fuzzy bridge is an arc whose removal from the fuzzy graph reduces the strength of connectedness between some pair of nodes.

In this paper we put forward a criterion by which an arc will be a fuzzy bridge, a-strong, a fuzzy bond in G as well as Gc.

\section{Preliminaries}

The following basic definitions are taken from.[9] A fuzzy graph is a pair $G:(\sigma, \mu)$, where $\sigma$ is a fuzzy subset of a set $V$ and $\mu$ is a fuzzy relation on $\sigma$, i.e., $\mu(x, y) \leq \sigma(x) \wedge \sigma(y), \forall x, y \in V$. We assume that $V$ is finite and nonempty, $\mu$ is reflexive and symmetric. In all the examples $\sigma$ is chosen suitably. Also, we denote the underlying crisp graph by $G^{*}:\left(\sigma^{*}, \mu^{*}\right)$, where $\sigma^{*}=\{u \in V: \sigma(u)>0\}$ and $\mu^{*}=\{(u, v)$ $\in V X V: \mu(u, v)>0\} . H=(\tau, v)$ is called a partial fuzzy subgraph of $G$ if $\tau$ $\subseteq \sigma$ and $\mathrm{v} \subseteq \mu$. We call $H:(\tau, \mathrm{v})$ a fuzzy subgraph of $G:(\sigma, \mu)$ if $\mathrm{\tau}(u)=$ $\sigma(u)$. The strength of connectedness between two nodes $\mathrm{x}$ and $\mathrm{y}$ is defined as the maximum of the strengths of all paths between $x$ and $y$ and is denoted by $\operatorname{CONN}_{G}(x, y)$. An arc $(x, y)$ is called a bridge in $G$ if the removal of $(x, y)$ reduces the strength of connectedness between some pair of nodes of G. A connected fuzzy graph G is called a fuzzy tree if it contains a spanning subgraph $\mathrm{F}$ which is a 
tree such that, for all edges $(x, y)$ not in $F, \mu(x, y)<\operatorname{CONN}_{F}(x, y)$. A path $P$ of length $n$ is a sequence of distinct nodes $u_{0}, u_{1}, u_{2}, \ldots . . u_{n}$ such that $\mu\left(\mathrm{u}_{\mathrm{i}-1}, \mathrm{u}_{\mathrm{i}}\right)>0$ and degree of membership of a weakest arc is defined as its strength. If $\mathrm{u}_{0}=\mathrm{u}_{\mathrm{n}}$ and $\mathrm{n} \geq 3$ then $\mathrm{P}$ is called a cycle and a cycle $P$ is called a fuzzy cycle if it contains more than one weakest arc. Let $G:(\sigma, \mu)$ be any f-graph. A set of strong arcs $E$ $=\left\{\mathrm{e}_{1}, \mathrm{e}_{2}, \ldots \ldots . \mathrm{e}_{\mathrm{n}}\right\}$ where $\mathrm{e}_{\mathrm{i}}=\left(\mathrm{u}_{\mathrm{i}}, \mathrm{v}_{\mathrm{i}}\right)$ is said to be a fuzzy arc cut (FAC)[8] if either $\operatorname{CONN}_{G-E}(x, y)<\operatorname{CONN}_{G}(x, y)$ for some pair of nodes $x, y$ in $\sigma^{*}$ with at least one of $x$ or $y$ is different from both $u_{i}$ and $v_{i} ; i=1,2, \ldots, n$, or $\mathrm{G}-\mathrm{E}$ is disconnected. If there are $\mathrm{n}$ arcs in $\mathrm{E}$ then it is called an n-FAC. Among all fuzzy arc cuts, an arc cut with one arc (1-FAC) is a special type of fuzzy bridge; a 1-FAC is called a fuzzy bond (f-bond).[8] In a fuzzy tree the concepts of fuzzy bridge, a-Strong arc, f-bond coincides.[8]

An $\operatorname{arc}(x, y)$ in $G$ is a strong arc if its strength is greater than or equal to $\operatorname{CONN}_{\mathrm{G}-(x, y)}(x, y)$. The different types of strong arcs in $G$ are mentioned here. Arc $(x, y)$ is a- Strong if $\rho(x, y)>\operatorname{CONN}_{G-(x, y)}(x, y)$. $\operatorname{Arc}(x, y)$ is $\beta$-Strong if $\rho(x, y)=\operatorname{CONN}_{G-(x, y)}(x, y)$. Arc $(x, y)$ is a $\delta$-arc if $\rho(x, y)<\operatorname{CONN}_{G-(x, y)}(x, y) \cdot[7]$

The complement of a fuzzy graph [5] $\mathrm{G}=(\sigma, \mu)$ is a fuzzy graph $\mathrm{G}^{\mathrm{c}}=$ $\left(\sigma^{c}, \mu^{c}\right)$ where $\sigma^{c}=\sigma$ and $\mu^{c}(\mathrm{u}, \mathrm{v})=\sigma(\mathrm{u})^{\wedge} \sigma(\mathrm{v})-\mu(\mathrm{u}, \mathrm{v})$ and a node in $\mathrm{G}$ is called a cut node if its removal reduces the strength of connectedness between some other pair of nodes of G.

Proposition 1 Let $G=(\sigma, \mu)$ be a fuzzy graph. If an $\operatorname{arc}(x, y)$ is a bridge (a-strong) in $\mathrm{G}$ and $\mathrm{Gc}^{\mathrm{c}}$ then $\mathrm{CONN}_{\mathrm{G}}(\mathrm{x}, \mathrm{y})+\mathrm{CONN}_{\mathrm{G}} \mathrm{c}(\mathrm{x}, \mathrm{y})=\wedge[\sigma(\mathrm{x}), \sigma(\mathrm{y})]$

Proof Suppose $(x, y)$ be a bridge in $G$ and $G^{c}$.

Then $\mathrm{CONN}_{\mathrm{G}}(\mathrm{x}, \mathrm{y})+\mathrm{CONN}_{\mathrm{G}} \mathrm{c}(\mathrm{x}, \mathrm{y})=\mu(\mathrm{x}, \mathrm{y})+\mu \mathrm{c}(\mathrm{x}, \mathrm{y})$

$$
\begin{aligned}
& =\mu(x, y)+\wedge[\sigma(x), \sigma(y)]-\mu(x, y) \\
& =\wedge[\sigma(x), \sigma(y)]
\end{aligned}
$$




\section{Example: 1}

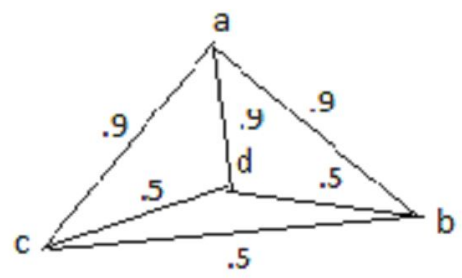

G

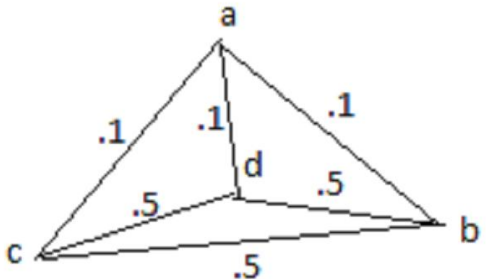

$G^{c}$

In the above fuzzy graphs $\operatorname{CONN}_{\mathrm{G}}(\mathrm{a} \cdot \mathrm{b})+\mathrm{CONN}_{\mathrm{G}} \mathrm{c}(\mathrm{a}, \mathrm{b})=1$. But $(a, b)$ is a bridge in $G$ but it is not a bridge in $G^{c}$. It is to be noted that $\mathrm{Gc}^{\mathrm{c}}$ is not a fuzzy tree. So theorem 2 is true only if $\mathrm{G}$ and $\mathrm{Gc}^{\mathrm{c}}$ are fuzzy trees.

The converse of this result is true only when G and Gc are fuzzy trees. This part is proved in the following theorem.

Proposition 2 Suppose $G$ and $G^{c}$ are fuzzy trees such that $\operatorname{CONN}_{G}(x, y)+\operatorname{CONN}_{G} c(x, y)=\wedge[\sigma(x), \sigma(y)]$, then $(x, y)$ will be a bridge(a-strong, fuzzy bond) in $\mathrm{G}$ and $\mathrm{G}^{\mathrm{c}}$

Proof We use a contra positive argument. Assume that $(x, y)$ is not a bridge in $G$ and $G^{c}$ simultaneously and we prove that $\operatorname{CONN}_{\mathrm{G}}(\mathrm{x}, \mathrm{y})+\mathrm{CONN}_{\mathrm{G}} \mathrm{c}(\mathrm{x}, \mathrm{y}) \neq \wedge[\sigma(\mathrm{x}), \sigma(\mathrm{y})]$

We know that $G=(\mu, \rho)$ is a fuzzy tree if and only if these statements are equivalent.

1) $(x, y)$ is a bridge in G. 2) $\operatorname{CONN}_{G}(x, y)=\rho(x, y)$.

Case $1(x, y)$ is a bridge in $G$ but not in $G^{c}$.

Using (1) we get, $\operatorname{CONN}_{\mathrm{G}}(\mathrm{x}, \mathrm{y})=\mu(\mathrm{x}, \mathrm{y})$ and $\mathrm{CONN}_{\mathrm{G}} \mathrm{c}(\mathrm{x}, \mathrm{y}) \neq \mu \mathrm{c}(\mathrm{x}, \mathrm{y})$.

Add above equations to get 
Mapana J Sci, 10, 2(2011) Types of Arcs in Complement of a Fuzzy Graph

$$
\begin{array}{r}
\operatorname{CONN}_{\mathrm{G}}(\mathrm{x}, \mathrm{y})+\mathrm{CONN}_{\mathrm{G}}^{\mathrm{c}}(\mathrm{x}, \mathrm{y}) \neq \mu(\mathrm{x}, \mathrm{y})+\mu \mathrm{c}(\mathrm{x}, \mathrm{y}) \\
\operatorname{CONN}_{\mathrm{G}}(\mathrm{x}, \mathrm{y})+\mathrm{CONN}_{\mathrm{G}} \mathrm{c}(\mathrm{x}, \mathrm{y}) \neq \wedge[\sigma(\mathrm{x}), \sigma(\mathrm{y})]
\end{array}
$$

Case $2(x, y)$ is not a bridge in $G$ but is a bridge in $G^{c}$.

Using (1) we get, $\operatorname{CONN}_{\mathrm{G}}(\mathrm{x}, \mathrm{y}) \neq \mu(\mathrm{x}, \mathrm{y})$ and $\mathrm{CONN}_{\mathrm{G}} \mathrm{c}(\mathrm{x}, \mathrm{y})=\mu \mathrm{c}(\mathrm{x}, \mathrm{y})$. Add above equations to get

$$
\begin{aligned}
& \operatorname{CONN}_{G}(x, y)+\operatorname{CONN}_{G} c(x, y) \neq \mu(x, y)+\mu c(x, y) \\
& \operatorname{CONN}_{G}(x, y)+\operatorname{CONN}_{G} c(x, y) \neq \wedge[\sigma(x), \sigma(y)]
\end{aligned}
$$

Corollary 1 Suppose $G=(\sigma, \mu)$ be a fuzzy graph such that $G$ and $G^{c}$ are fuzzy trees. If $\operatorname{CONN}_{G}(x, y)+\operatorname{CONN}_{G} c(x, y)=1$, then $(x, y)$ is a bridge(a-strong, fuzzy bond) in $\mathrm{G}$ and $\mathrm{G}^{\mathrm{c}}$.

Remark 1 A fuzzy bridge is also an a-strong arc in a fuzzy graph [7]. If $G$ is a fuzzy tree then every bridge of $G$ is also a fuzzy bond of $\mathrm{G}[6]$.

\section{Example 2}

$\mathrm{G}$ and $\mathrm{G}^{\mathrm{c}}$ are fuzzy trees. Arc $(\mathrm{c}, \mathrm{b})$ is a bridge in $\mathrm{G}$ and not a bridge in $G^{c}$ and $\operatorname{CONN}_{G}(c, b)+\operatorname{CONN}_{G}(c, b) \neq 1$. Arc $(a, c)$ is a bridge in $G$ and $G^{c}$ and $\mathrm{CONN}_{\mathrm{G}}(\mathrm{a} . \mathrm{c})+\mathrm{CONN}_{\mathrm{G}} \mathrm{c}(\mathrm{a}, \mathrm{c})=1$

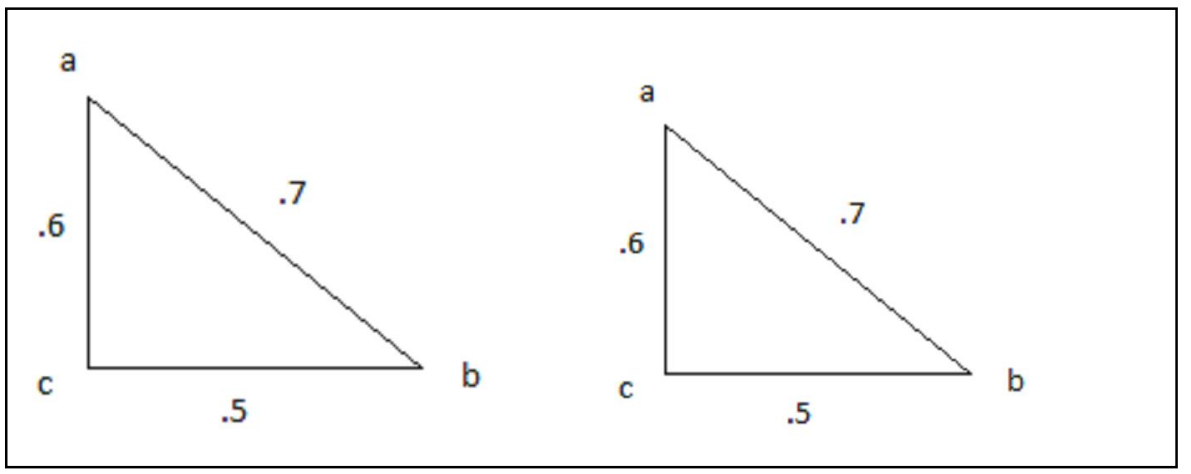


Proposition 3 Let $G=(\mu, \rho)$ be a fuzzy graph and suppose $(x, y)$ is a strong in $G$ and $G^{c}$ then $\mathrm{CONN}_{\mathrm{G}-(\mathrm{x}, \mathrm{y})}(\mathrm{x}, \mathrm{y})+\mathrm{CONN}_{\mathrm{G}^{\mathrm{c}}}-(\mathrm{x}, \mathrm{y})(\mathrm{x}, \mathrm{y})<$ $\operatorname{Min}[\mu(\mathrm{x}), \mu(\mathrm{y})]$

Proof $(x, y)$ is a - strong in Gand Gc.

Hence from definitions we get,

$$
\rho(x, y)>\operatorname{CONN}_{G-(x, y)}(x, y) \text { and } \rho^{c}(x, y)>\operatorname{CONN}_{G^{c}}-(x, y)(x, y) .
$$

Adding these equations

$$
\mathrm{CONN}_{\mathrm{G}-(x, y)}(x, y)+\operatorname{CONN}_{\mathrm{G}^{c}-(x, y)}(x, y)<\rho(x, y)+\rho^{c}(x, y)
$$

Therefore, $\mathrm{CONN}_{\mathrm{G}-(\mathrm{x}, \mathrm{y})}(\mathrm{x}, \mathrm{y})+\mathrm{CONN}_{\mathrm{G}}{ }^{-}(\mathrm{x}, \mathrm{y})(\mathrm{x}, \mathrm{y})<\operatorname{Min}[\mu(\mathrm{x}), \mu(\mathrm{y})]$

Proposition 4 Let $G=(\mu, \rho)$ be a fuzzy graph and suppose $(x, y)$ is $\beta$-strong in $G$ and $G^{c}$. Then $\mathrm{CONN}_{\mathrm{G}-(x, y)}(x, y)+\operatorname{CONN}_{\mathrm{G}^{\mathrm{c}}}-(\mathrm{x}, \mathrm{y})(\mathrm{x}, \mathrm{y})=$ $\wedge[\mu(\mathrm{x}), \mu(\mathrm{y})]$

Proof $(x, y)$ is $\beta$ - strong in $G$ and $G$ c.

Hence from definitions we get, $\rho(x, y)=\operatorname{CONN}_{G-(x, y)}(x, y)$ and $\rho^{c}(x, y)=\operatorname{CONN}_{G^{c}-(x, y)}(x, y)$.

Adding these equations,

$\operatorname{CONN}_{\mathrm{G}-(x, y)}(x, y)+\operatorname{CONN}_{G^{c}-(x, y)}(x, y)=\rho(x, y)+\rho^{c}(x, y)$ Therefore, $\mathrm{CONN}_{\mathrm{G}-(\mathrm{x}, \mathrm{y})}(\mathrm{x}, \mathrm{y})+\mathrm{CONN}_{\mathrm{G}^{\mathrm{c}}-(\mathrm{x}, \mathrm{y})}(\mathrm{x}, \mathrm{y})=\wedge[\mu(\mathrm{x}), \mu(\mathrm{y})]$

Proposition 5 Let $G=(\mu, \rho)$ be a fuzzy graph and suppose $(x, y)$ is $\delta$-arc in $G$ and $G^{c}$. Then $\operatorname{CONN}_{G-(x, y)}(x, y)+\operatorname{CONN}_{G^{c}}-(x, y)(x, y)>\wedge[$ $\mu(\mathrm{x}), \mu(\mathrm{y})]$

Proof $(x, y)$ is $\delta-\operatorname{arc}$ in $G$ and $G$ c.

Hence from definitions we get, $\rho(x, y)<\operatorname{CONN}_{G-(x, y)}(x, y)$ and $\rho^{c}(x, y)<\operatorname{CONN}_{G^{c}-(x, y)}(x, y)$.

Adding these equations,

$$
\mathrm{CONN}_{\mathrm{G}-(x, y)}(x, y)+\operatorname{CONN}_{G^{c}-(x, y)}(x, y)<\rho(x, y)+\rho^{c}(x, y)
$$

Therefore, $\mathrm{CONN}_{\mathrm{G}-(\mathrm{x}, \mathrm{y})}(\mathrm{x}, \mathrm{y})+\mathrm{CONN}_{\mathrm{G}}{ }^{\mathrm{c}}-(\mathrm{x}, \mathrm{y})(\mathrm{x}, \mathrm{y})<^{\wedge}[\mu(\mathrm{x}), \mu(\mathrm{y})]$ 
Mapana J Sci, 10, 2(2011) Types of Arcs in Complement of a Fuzzy Graph

\section{References}

[1] A. Rosenfeld. "Fuzzy graphs" in Fuzzy Sets and their Applications to Cognitive and Decision Processes, Zadeh, L.A., Fu, K.S., Tanaka, K., Shimura, M. Eds. New York: Academic Press, 1975, pp. 77-95.

[2] K.R. Bhutani and A. Rosenfeld, "Fuzzy end nodes in fuzzy graphs," presented at Information Sciences, 2003, pp. 323-326.

[3] K.R. Bhutani, J. Mordeson and A. Rosenfeld. "On Degrees of End Nodes and Cut Nodes in Fuzzy Graphs." Iranian Journal of Fuzzy Systems, vol I, no. 1, pp. 57-64, 2004.

[4] M.S. Sunitha \& A. Vijayakumar. "A characterization Of Fuzzy Trees," presented at Information Sciences, 1999, pp.293-300.

[5] M.S. Sunitha and A. Vijayakumar. "Complement of a Fuzzy Graph," Indian Journal of Pure and Applied Mathematics, vol. 33, no. 9, pp.451-1464, 2002.

[6] M.S. Sunitha and A. Vijayakumar. "Blocks in Fuzzy Graphs." The Journal of Fuzzy Mathematics, vol. 13, vo. 1, pp. 13-23, 2005.

[7] S. Mathew and M.S. Sunitha. "Types of arcs in a fuzzy graph," presented at Information Sciences, 2009, pp.1760-1768.

[8] S. Mathew and M.S. Sunitha. "Node Connectivity \& Arc Connectivity of Fuzzy Graphs," presented at Information Sciences, 2010

[9] J.N. Mordeson and P.S. Nair, Fuzzy Graphs and Fuzzy Hypergraphs, Physica-Verlag, 2000. 